\section{RWMODEL II: Computer simulation of the Rescorla-Wagner model of Pavlovian conditioning}

\author{
OTTMAR V. LIPP, JOHN STEPHENS, \\ and TIMOTHY A. SMITH \\ University of Queensland, Queensland, Australia
}

RWMODEL II simulates the Rescorla-Wagner model of Pavlovian conditioning. It is written in Delphi and mins under Windows 3.1 and Windows 95. The program was designed for novice and expert users and can be employed in teaching, as well as in research. It is user friendly and requires a minimal level of computer literacy but is sufficiently flexible to permit a wide range of simulations. It allows the display of empirical data, against which predictions from the model can be validated.

The Rescorla-Wagner model (Rescorla \& Wagner, 1972 ) is one of the more powerful formal models developed in psychology. Nevertheless, it is low in computational demand, to the extent that simulations can be calculated by hand with the aid of a desk calculator. Although it has well-known limits that are inherent in its design, the model accommodates a wide variety of conditioning phenomena, reviewed by Miller, Barnet, and Grahame (1995). These characteristics make it an ideal example not only for the teaching of the psychology of learning, but also for the teaching of psychology in general.

The Rescorla-Wagner model was designed to account for the phenomenon of blocking (Kamin, 1968), the finding that pairings of the conditioned stimulus (CS) and the unconditioned stimulus (US) are not sufficient for the emergence of a conditional response. The model accounts for this result by assuming that a single US can support only a limited extent of conditioning. Learning is conceptualized as the change in the associative strength of a CS that occurs on a trial-by-trial basis. It is a function of the difference between the extent to which the US can support learning $\left(\lambda_{\text {US }}\right)$ and the extent to which it is predicted by all CSs that are presented on a particular trial $\left(V_{\mathrm{all}}\right)$. The change in the associative strength of a CS on a single trial is modulated by characteristics of the CS $\left(\alpha_{\mathrm{CS}}\right)$ and the US $\left(\beta_{\mathrm{US}}\right)$, such as intensity or preparedness, which are represented by two fixed parameters. Thus, the change in the associative strength of CS A that occurs on trial $n$ can be expressed as

$$
\Delta V_{\mathrm{A}(n)}=\alpha_{\mathrm{A}} * \beta_{\mathrm{US}(n)} *\left(\lambda_{U S(n)}-V_{\text {all(n) }}\right) .
$$

Correspondence concerning this article should be addressed to $\mathrm{O}$. V. Lipp, School of Psychology, University of Queensland, QLD, 4072, Australia (e-mail: o.lipp@psy.uq.edu.au).
$V_{\text {all }(n)}$ is the sum of the associative strengths of all the CSs that are presented on trial $n$. After each trial, the associative strength of each CS that was presented on this trial is updated:

$$
V_{\mathrm{CS}(n+1)}=V_{\mathrm{CS}(n)}+\Delta V_{\mathrm{CS}(n)} .
$$

The preset simulation program is based on a previous version (Lachnit, Schneider, Lipp, \& Kimmel, 1988) that runs under DOS. The previous program had features similar to the present one, but was less user friendly. The present program complements a simulation software by Mercier (1996) that, in addition to the simulation of the Rescorla-Wagner model, includes the options of simulating a second conditioning model, the Pearce and Hall (1980) model, and of calculating contingency judgments. This software has a broader scope than the present one, but the added options seem to be confusing to novice users. Moreover, it does not include the option of comparing predicted values of associative strength with observed data, a feature that has been regarded as one of the strengths of the Lachnit et al. software. The present software was developed with the intention of providing an easy-to-use application of the Rescorla-Wagner model that can be used by students with only minimal computer literacy such as those encountered in large undergraduate classes, as well as by researchers who work in the field of Pavlovian conditioning. It was designed to be easily transferable across computers, so that students can copy it for use on their home computers, and to be largely self-explanatory. On the other hand, it was designed to be flexible enough for the simulation of almost any conditioning paradigm and to include the option to display empirical data. The latter allows the matching of predicted values of associative strength with observed changes in behavior.

RWMODEL II is menu driven. The opening menu allows either the generation of a new simulation or loading an existing simulation stored on a file. Selecting either option leads to the "Main" menu, which represents the details of a particular simulation (see Figure 1). The "Main" menu allows the specification of stimulus parameters $\alpha$ for four CSs and of $\beta$ parameters for the presence or the absence of the US. The table in the center of the "Main" menu allows the coding of up to 100 trials, indicating whether the CSs and the US were presented on a particular trial. In addition, values for observed data can be entered. The output is determined by ticking the boxes next to the "graph selection" menu. Ticking one box requests the associative strengths for a single stimulus, whereas ticking two or more requests the associative strengths for a compound stimulus consisting of the selected elements. The on-screen output allows for plots of the graphs or the tabulation of the numeric simulation results, together with the description of the experimental design. Up to four graphs and a data graph can be plotted simultaneously. The table of results can be saved as a text file, as can the 


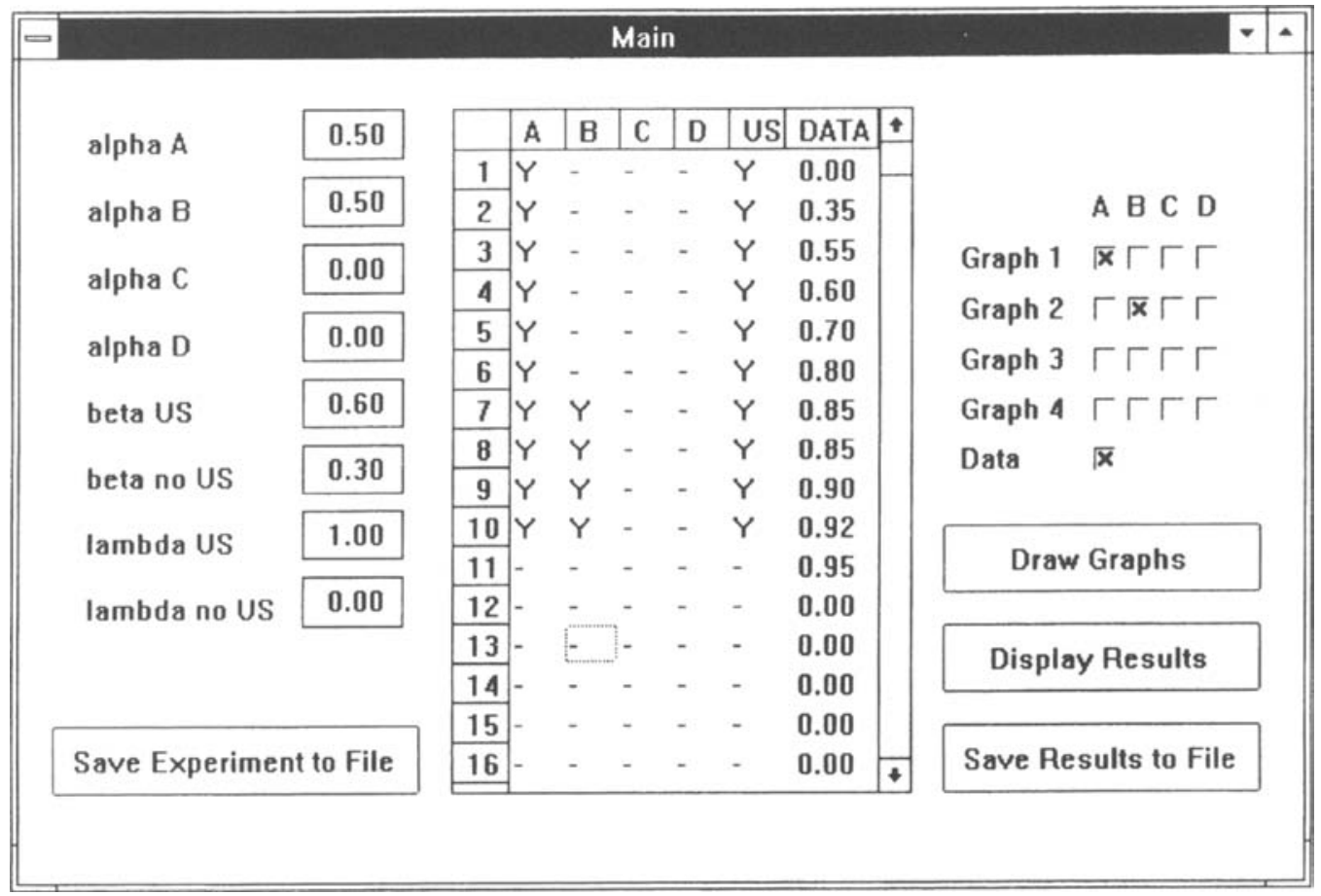

Figure 1. Layout of the program's "Main" menu.

description of the experiment. The latter can be used as input for future simulations. Direct printing of the graphs is not possible; however, the graphs can be captured off the screen for printing.

The program is available on request, free of charge, from the first author.

\section{REFERENCES}

Kamin, L. J. (1968). "Attention-like" processes in classical conditioning. In M. R. Jones (Ed.), Miami symposium on the prediction of behavior: Aversive stimulation (pp. 9-31). Miami: University of Miami Press.

LAChNit, H., Schneider, R. L., LiPP, O. V., \& Kimmel, H. D. (1988). RWMODEL: A program in Turbo Pascal for simulating predictions based on the Rescorla-Wagner model of classical conditioning. Behavior Research Methods, Instruments, \& Computers, 20, 413-415.
Mercier, P. (1996). Computer simulations of the Rescorla-Wagner and Pearce-Hall models in conditioning and contingency judgement. Behavior Research Methods, Instruments, \& Computers, 28, 55-60.

Miller, R. R., Barnet, R. C., \& Grahame, N. J. (1995). Assessment of the Rescorla-Wagner model. Psychological Bulletin, 117, 363386.

Pearce, J. M., \& Hall, G. (1980). A model for Pavlovian learning: Variations in the effectiveness of conditioned, but not of unconditioned stimuli. Psychological Review, 87, 532-552.

Rescorla, R. A., \& WAGNER, A. R. (1972). A theory of Pavlovian conditioning: Variations in the effectiveness of reinforcement and nonreinforcement. In A. H. Black \& W. F. Prokasy (Eds.), Classical conditioning $I$ ( (pp. 64-99). New York: Appleton-Century-Crofts.

(Manuscript received August 18, 1998; revision accepted for publication April 27, 1999.) 